5. HISTORIA DE LOS DERECHOS PATRIOS DE AMÉRICA 

Revista de Estudios Histórico-Jurídicos

[Sección Historia de los Derechos Patrios de América]

XXXIII (Valparaíso, Chile, 2011)

[pp. 487 - 510]

\section{LA VISIÓN DE LA DIPLOMACIA ALEMANA SOBRE UN MOMENTO DE CRISIS DEL RÉGIMEN DE GOBIERNO CHILENO: LA CAÍDA DEL PRESIDENTE CARlOS IBÁNEZ DEL CAMPO EN JULIO DE 1931}

["The German Diplomacy Vision Regarding a Moment of Crisis of the Chilean Government Regime: the Fall of President Carlos Ibáñez del Campo in July, 1931"]

\section{Enrique Brahm García* \\ Universidad de los Andes}

\section{RESUMEN}

Teniendo como fuente fundamental la documentación conservada en el Politischen Archiv des Auswärtigen Amts (Archivo político del Ministerio de Relaciones Exteriores alemán con sede en Berlín), se analiza la visión de la diplomacia alemana ante la crisis que llevó a la caída del presidente Carlos Ibáńez y al comienzo de un período de inestabilidad política e institucional que recién se superaría a fines del año 1932.

Palabras clave

Ibáñez - Crisis - Intervención militar - República socialista.

\section{ABSTRACT}

Based on the documentation preserved at the Politischen Archiv des Auswärtigen Amts (Files on the Foreign Policy of the Federal Republic of Germany with seat at Berlin), as primary source, the way in which the German diplomacy conceived the crisis that led to the fall of President Carlos Ibáñez and to the beginning of a period of political and institutional instability that would only be overcome by the end of 1932 is analyzed.

\section{KeYwords}

Ibáñez - Crisis - Military intervention - Socialist Republic.

ReCibido el 12 de mayo y ACEPTADO el 14 de julio de 2011

* Profesor de Historia del Derecho en la Facultad de Derecho de la Universidad de los Andes y Director del Instituto de Historia de la misma Universidad. Dirección postal: Universidad de los Andes, San Carlos de Apoquindo 2200, Las Condes, Santiago de Chile. Correo electrónico: ebrahm@uandes.cl 


\section{INTRODUCCIÓN}

Carlos Ibáñez del Campo se constituyó desde muy temprano como el hombre fuerte del movimiento militar que se inició con el "ruido de sables" de los primeros días de septiembre del año 1924, que puso fin al régimen parlamentario y dio comienzo a una nueva etapa en la historia de Chile ${ }^{1}$. En efecto, "la irrupción de los militares en la política significaba una verdadera revolución, impulsada por una fuerza que no era sólo circunstancial o local, sino que se enraizaba en un movimiento de dimensiones mundiales. De ahí el peso específico con el que entraban a la arena política chilena, Ibáñez y quienes lo seguían" ${ }^{2}$. De esta forma, durante los años que van de 1924 a 1932, marcados por la presencia constante y decisiva de los militares en la política, Chile fue transformado de raíz. Y en ese proceso de radicales cambios Carlos Ibáñez jugó un papel clave ${ }^{3}$. Primero sería crucial su accionar para provocar la renuncia del presidente Arturo Alessandri; luego para defender el programa de la juventud militar, constituida en Junta Militar, frente a la Junta de Gobierno presidida por el general Luis Altamirano, hasta gestar la caída de esta con el golpe militar de 23 de enero de 1925; propiciaría luego la vuelta de Alessandri, quien quedaría supeditado a los militares, de forma evidente al verse obligado a mantener como ministro de Guerra al mismo Ibáñez ${ }^{4}$, el cual además estuvo a punto de presentarse como candidato a presidente de la República en las primeras elecciones que tuvieron lugar bajo la vigencia del nuevo texto constitucional5 $^{5}$; seguiría como ministro de Guerra y representante del movimiento militar durante el gobierno de Emiliano Figueroa, del que terminó por ser su último ministro del Interior y vicepresidente de la República, para terminar siendo elegido presidente de la República en las elecciones de mayo de 1927 con el apoyo de la

${ }^{1}$ Entre las obras clásicas de la época para ese tema pueden destacarse: MonREAL, Enrique, Historia completa y documentada del periodo revolucionario 1924-1925 (Santiago, Imprenta Nacional, 1929); Aldunate Phillips, Raúl, Ruido de sables (Santiago, Escuela Lito-tipográfica "La Gratitud Nacional", s.d.); Ahumada, Arturo, El Ejército y la revolución de 5 de septiembre de 1924 (Santiago, 1931); BennetT, Juan Pablo, La revolución de 5 de septiembre de 1924 (Santiago, Balcells y Cía. Editores, s.d.); SÁEZ, Carlos, Recuerdos de un soldado. El Ejército y la política (Santiago, Biblioteca Ercilla, 1933); Rodríguez MendozA, Emilio, El golpe de Estado de 1924. Ambiente y actores (Santiago, Ercilla, 1938).

${ }^{2}$ Brahm García, Enrique-Bertelsen Repetto, Raúl-Amunátegui Echeverría, Andrés, Régimen de gobierno en Chile. ¿Presidencialismo o parlamentarismo? 1925-1973 (Santiago, Editorial Jurídica de Chile, 2002), p. 39.

${ }^{3}$ Respecto a los años de formación de Carlos Ibáñez puede consultarse: BRAHM GARCía, Enrique, Carlos Ibáñez del Campo: el surgimiento de un caudillo político revolucionario, en, Arancibia Mattar, Jaime-Martínez Estay, José Ignacio (coordinadores), La primacía de la persona. Estudios en homenaje al profesor Eduardo Soto Kloss (Santiago, LegalPublishing, 2009), pp. 121/136; Brahm García, Enrique, La carrera militar de Carlos Ibáñez del Campo 1909-1919, en Boletín de la Academia Chilena de la Historia, 119 (Santiago, 2010), pp. 15-54.

${ }^{4}$ VIaL, Gonzalo, Historia de Chile (1891-1973), III: Arturo Alessandri y los golpes militares (1920-1925) (Santiago, Editorial Santillana del Pacífico, 1986).

${ }^{5}$ Brahm García, Enrique, La elección presidencial de 1925. El candidato equivocado, en, SAN Francisco, Alejandro y Soto, Angel, Camino a la Moneda. Las elecciones presidenciales en la historia de Chile 1920-2000 (Santiago, Centro de Estudios Bicentenario, 2005), pp. 39-79. 
inmensa mayoría de la ciudadanía: obtuvo el $98 \%$ de los votos en una elección en la que había participado el $83 \%$ de los ciudadanos inscritos ${ }^{6}$.

Durante esos años, sobre todo los primeros de su presidencia, Ibáñez desarrolló una gigantesca obra de transformación del Chile tradicional. Fernando Silva Vargas hace un buen resumen de la misma para concluir que, "bajo esta sacudida, bajo esta profunda revolución causada por la labor del gobierno, subyace un hecho poco advertido y que constituye, sin duda, el de mayor envergadura en la institucionalidad chilena de este siglo: la transformación del estado en agente

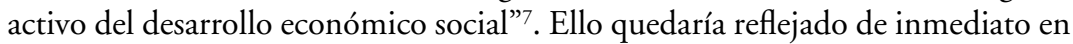
el gran crecimiento que tuvo el aparato estatal en esos años, pero, más todavía, en la aparición de un aparato paraestatal que daría al estado la posibilidad de crear herramientas de gran flexibilidad que le permitirían incursionar en áreas que parecían ajenas por completo al interés de los gobiernos de turno ${ }^{8}$.

En el mismo sentido, Mario Góngora concluye, por su parte, que: "Ibáñez, como Alessandri, han dejado pues una huella decisiva en la estructura del Estado: la concepción de que el estado debe tener una actitud protectora para todos los estratos de la sociedad, en la medida que estén involucrados en el trabajo material o administrativo, es necesario ir creando nuevos organismos estatales o para-estatales y con ello incrementar cuantitativamente la administración pública"9.

De esta forma, un gobierno sólido y realizador como el de Carlos Ibáñez, con el que se consolidaba el ingreso a la arena política de los sectores medios de la sociedad, que tomaba una serie de medidas para proteger a los sectores más débiles de la misma y que contaba con un fuerte apoyo de las fuerzas armadas, parecía que no tendría problemas en llegar al final de su período. Todavía cuando terminaba el año 1929 y hasta comienzos de 1930, ni los sectores más extremos de la oposición, duramente perseguidos por el aparato policial del gobierno ${ }^{10}$, podían imaginar la posibilidad de ver derrumbarse la así llamada "dictadura" ${ }^{11}$. Sin embargo y de manera repentina se produciría la caída el año 1931. ¿Por qué?

Naturalmente la razón más evidente para explicar el desplome del gobierno de Ibáñez se relaciona con los efectos que tuvo en Chile la "gran depresión” del

${ }^{6}$ VIAL, Gonzalo, Historia de Chile (1891-1973) (Santiago, Editorial Fundación, 1996), IV: La dictadura de Ibáñez (1925-1931); y Silva, F. - Villalobos, S. - Estellé, P., Historia de Chile, (Santiago, Editorial Universitaria, 1976), IV, p. 913; y NunN, Frederick M., La elección presidencial de 1927. Un final esperado y profético a la vez, en SAN FRANCISCO, Alejandro - SOTO, Ángel, cit. (n. 5), pp. 81-116.

${ }^{7}$ Silva, Silva, F. - Villalobos, S. - Estellé, P., Historia, cit. (n. 6), p. 920.

${ }^{8}$ Bravo Lira, Bernardino, Historia de las instituciones políticas de Chile e Hispanoamérica (Santiago, Editorial Jurídica de Chile, 1986), pp. 283 ss.

${ }^{9}$ Góngora, Mario, Ensayo histórico sobre la noción de Estado en Chile en los siglos XIX y XX (Santiago, Ediciones La ciudad, 1981), p. 88.

${ }^{10}$ Cfr. Loveman, Brian - Lira, Elisabeth, Los actos de la dictadura. Comisión investigadora, 1931 (Santiago, LOM Ediciones, 2006).

${ }^{11}$ Vial, Gonzalo, Carlos Ibáñez del Campo (Santiago, Ediciones Aifos Ltda., 2007), p. 85: "No obstante diversos complots de distinta envergadura, don Carlos, ya general desde 1927, se mantuvo firme y con el país en un puño hasta comienzos de 1931. Ello, aunque a partir de 1929 el mundo entero fuese presa del más devastador fenómeno económico-financiero del siglo XX: la Gran Crisis [...]". 
año 1929. En ello coinciden la mayoría de los autores que han estudiado el tema. En un conocido "manual" que cubre la historia del siglo XX chileno, se señala que Chile fue "el país más afectado por la crisis en su comercio internacional"; y se añade que "El valor de las exportaciones en 1932 llegó a solo el 12\% de lo que se exportaba en 1929”. Más todavía, "uno de los efectos de más largo plazo de la crisis mundial en la economía del país fue la desventajosa relación en los términos de intercambio, es decir, entre el precio de las exportaciones y el de las importaciones. Para América Latina esta pérdida llegó a situarse entre un 21 y un $45 \%$ en los años que van de 1929 a 1933; en el caso de Chile la cifra llegó al 36\%. Al mismo tiempo, los préstamos que el país recibía de los Estados Unidos se secaron drásticamente: de los 443 millones de pesos recibidos en 1929, se pasó a 22.4 millones en 1932, hasta llegar a cero en 1933 [...]. Los efectos sociales no se hicieron esperar"12.

En opinión de Simon Collier y William F. Sater: "Ibáñez no tuvo que hacer frente a esta crisis de forma inmediata. El dinero de los préstamos externos todavía estaba llegando. Durante algunos meses, los negocios se mantuvieron como siempre. En 1930, de hecho, las importaciones aumentaron. A comienzos de 1931, con sus principales exportaciones postradas y sin los banqueros de Wall Street para que lo socorrieran, el hombre de La Moneda finalmente tuvo que enfrentarse a la realidad". Pero ya era tarde, las recetas económicas tradicionales que se aplicaron no dieron resultados y el colapso definitivo llegó con gran rapidez ${ }^{13}$.

En el mismo sentido se expresa Gonzalo Vial, al señalar que en Chile el impacto de la crisis se retardó "porque éramos un país pequeño, serio, tranquilo, gobernado con moderada dureza y que siempre había cumplido sus compromisos", y en el que la banca internacional siguió confiando. Hasta que esta "no nos prestó más y nos hundimos [...]. Era inevitable, cualquier cosa que hubiera hecho Ibáñez. Es cierto que se aferró quijotescamente a una moneda de oro que no podía sostener. Es cierto que rechazó economías que - según él - implicaban desarmar "su" nuevo Estado. Es cierto que el endeudamiento de Ramírez aparecía ahora descabellado. Pero, con o sin estos factores, la profundidad de la crisis chilena hacía inevitable un colapso casi fatal. Y ocurrió"14.

Buscando una explicación a lo anterior Joaquín Fermandois sostiene que "había un problema de fondo. El desarrollo durante el gobierno de Ibáñez se financió con créditos externos. Esto no es una novedad para economías "en desarrollo". El problema radicaba en que no estaban vinculadas a un proceso productivo que ayudara a cubrir la contratación de capital externo. La única manera de cumplir

\footnotetext{
${ }^{12}$ Correa - Figueroa - Jocelyn-Holt - Rolle - Vicuña, Historia del siglo XX chileno (Santiago, Sudamericana, 2001), p. 105.

${ }^{13}$ Collier, Simon - Sater, William F., Historia de Chile 1804-1994 (España, Cambridge University Press, 1998), p. 198. Cfr. STRawridge, Jr., George, Militarism and Nationalism in Chile 1920-1932 (University of Pennsylvania, Ph. D., 1968) (inédita), pp. 170 ss.

${ }^{14}$ Vial, Carlos Ibáñez del Campo, cit. (n. 11), p. 86. Cfr. para el desarrollo económico durante los primeros años del gobierno de Ibáñez, BERNEdo, Patricio, Prosperidad económica bajo Carlos Ibánez del Campo 1927-1929. La dimensión internacional de un programa económico de gobierno, en Historia, 24 (Santiago, 1989).
} 
las obligaciones de la deuda era... endeudándose más”. Pero, más todavía, según Fermandois: "no se puede ignorar el factor internacional en la crisis. Una economía en desarrollo que estaba reformándose, como la chilena, requería de un tiempo mayor de crecimiento en el exterior. Esperar que no vinieran recesiones, era total carencia de sentido de la realidad. Pero no era dable esperar lo que vino, la depresión más grave en términos de shock inmediato y global desde la Revolución Industrial"15.

Pero también la historiografía ha sabido reconocer la existencia de otros factores que servirían de detonante para precipitar la caída del presidente Carlos Ibáñez. Según Fernando Silva Vargas: "es innegable que el fracaso de Ibáñez estuvo vinculado a la crisis económica que comenzó a sentirse en Chile en 1930. Pero también es cierto que a aquellas dificultades se agregaron otras de índole política. Los extensos sectores, que entonces se sintieron interpretados por un gobierno realizador, no supieron agruparse para respaldarlo" ${ }^{16}$. Más adelante y a modo de conclusión, agregaba: "No puede negarse que la coyuntura económica fue especialmente desfavorable para Ibáñez, pero no cabe duda que ofició como "disparador" en la crisis política el elemento universitario, el intelectual y el profesional. Pagó así el caudillo el error de no haber sabido atraerlo, en el que en cambio no incurrieron los gobernantes autoritarios del siglo XIX"17.

Similares son las conclusiones a las que se llega en una tesis para licenciarse en historia dirigida a investigar precisamente la crisis que precipitó la caída del gobierno de Ibáñez. Este se habría mostrado "hábil para llegar al poder, pero no demostró la misma habilidad para mantenerse en él [...]. Desde que se desató la crisis hasta el último día que permaneció en el poder supeditó el accionar político al económico, impidiendo de esta manera lograr acuerdos con la oposición en los momentos más difíciles. Ibáñez jamás tuvo la intención de aglutinar las fuerzas que lo apoyaron para llegar a la Moneda en una gran entidad política, y sólo gracias a los consejos de sus asesores más directos, organizó la Crac, pero rápidamente se desvinculó de ella, volviendo a actuar sólo, sin el apoyo decidido de una masa organizada"18.

Resulta evidente de que si bien la crisis económica fue el gran detonante que precipitó la caída de Ibáñez, llevando al país cómo también al resto del mundo, a una situación límite y extrema, cómo se ha dado pocas veces, confluyeron también otros factores de menor alcance y hasta circunstanciales y personales. Bien lo ha resumido Fermandois al sostener que: "en 1931 Ibáñez no supo o no pudo responder con medidas políticas; para medidas económicas la caja estaba

\footnotetext{
${ }^{15}$ Fermandois, Joaquín, Mundo y fin de mundo. Chile en la politica mundial 1900-2004 (Santiago, Ediciones Universidad Católica de Chile, 2005), p. 110.

${ }^{16}$ Silva, Silva, Villalobos y Estellé, cit. (n. 6), vol. IV, p. 923.

${ }^{17}$ Silva, Silva, Villalobos y Estellé, cit. (n. 6) vol. IV, p. 926.

${ }^{18}$ Cordero Rebolledo, Raúl Andrés, Ibáñez y la crisis de 1930-1931, Tesis para optar al grado de Licenciado en Historia, Instituto de Historia P. Universidad Católica de Chile (Santiago, 1994 )(inédita), p. 115. Cfr. Bertolino Rendic, Mauricio, Primer gobierno del general Carlos Ibáñez del Campo (1927-1931), Tesis para optar al grado de Licenciado en Derecho, Facultad de Derecho P. Universidad Católica de Chile (Santiago, s.d.) (inédita), pp. 367 y 391.
} 
agotada. A una crisis ministerial, la presión externa de los exiliados, que hasta ahora sólo habían soñado conspiraciones, y la demanda de "la calle", terminaron por provocar la renuncia de Ibáñez antes que encarar una acción sanguinaria de incierto resultado" 19 .

Por su parte, y para terminar, Gonzalo Vial, concluye el grueso tomo que dedicó al primer gobierno de Carlos Ibáñez, preguntándose por el porqué "cedió la voluntad de resistir de Ibáñez" en la noche del 25 al 26 de julio de 1931. En su opinión habrían sido cinco las circunstancias que confluyeron en esa decisión: "Su mal estado de salud"; "la indecisión y abatimiento que solían cogerlo en los momentos claves [...] parálisis de la cual lo habían sacado, cada vez, sus lugartenientes más audaces"; "la ausencia, el año 31 -por motivos que hemos repetido demasiado-, de esos lugartenientes"; "la debilidad y concesiones al "enemigo" del equipo que ahora lo rodeaba"; "la resolución de que no continuase el derramamiento de sangre" 20 .

\section{LOS INFORMES DE LA DIPLOMACIA ALEMANA SOBRE LA SITUACIÓN EN CHILE}

Puede resultar de interés contrastar las conclusiones a que ha llegado la historiografía relativa al sorpresivo final del primer gobierno de Carlos Ibáñez, con los informes que en su momento enviaban los representantes del gobierno alemán en Chile a Berlín. Estos se conservan y se pueden revisar en el Politischen Archiv des Auswärtigen Amts (= PAAA; Archivo Político del ministerio de Relaciones Exteriores) en la capital alemana. Por lo demás Chile era para Alemania un país de particular interés y al que lo unían fuertes lazos desde el momento en que existía aquí una importante colonia alemana, que se había consolidado en la segunda mitad del siglo XIX ${ }^{21}$ y que el ejército, a partir de la llegada de Emilio Körner, estaba marcado por una fuerte impronta prusiana ${ }^{22}$.

Si bien se conserva en dicho Archivo alguna información sobre la intervención militar y los primeros años del gobierno de Ibáñez, años que coinciden con la última fase de relativa "normalidad” de la República de Weimar ${ }^{23}$, cuya figura más

${ }^{19}$ Fermandois, cit. (n. 15), p. 111.

${ }^{20}$ VIAL, Historia de Chile, cit. (n. 6), IV, p. 548. La opinión del mismo Ibáñez sobre las razones de su caída pueden verse en CORREA Prieto, Luis, El Presidente Ibáñez. La política y los políticos. Apuntes para la historia (Santiago, Editorial Orbe, 1962), pp. 152ss.

${ }^{21}$ Cfr. BlancPain, Jean Pierre, Les Allemands au Chili (1816-1945) (Köln-Wien, Böhlau Verlag, 1974); BlancPain, Jean Pierre, Los alemanes en Chile (1816-1945) (Santiago, Hachette,1985); Brahm García, Enrique, Manuel Montt y la colonización de Llanquihue, en, Manuel Montt educador, legislador, gobernante y magistrado. Estudios en conmemoración del bicentenario de su nacimiento (1809-2009) (Santiago, Fundación Manuel Montt, 2009), II, pp. 119ss.

${ }^{22}$ Cfr., entre otros, Brahm García, Enrique, Preparados para la guerra. Pensamiento militar chileno bajo influencia alemana 1885-1930 (Santiago, Ediciones Universidad Católica de Chile, 2003); y Arancibia Clavel, Patricia (Editora), Balart Páez, Francisco - Brahm García, Enrique - SAn Francisco, Alejandro, El Ejército de los chilenos 1540-1920, (Santiago, Editorial Biblioteca Americana, 2007).

${ }^{23}$ Kolb, Eberhard, Die Weimarer Republik (München, Oldenbourg, 2009). 
representativa e influyente fue Gustav Stresseman ${ }^{24}$, la mayoría de los informes y telegramas enviados por la Legación alemana corresponden a los años 1930-1932, cuándo se vivían los años finales de la República de Weimar y el régimen parlamentario alemán había dejado de funcionar. Durante ese período no se gobernaba en Alemania de acuerdo a las mayorías parlamentarias, sino en virtud de las facultades extraordinarias que daba al presidente de la República -el anciano mariscal Paul von Hindenburg ${ }^{25}$-, el artículo 48 de la Constitución ${ }^{26}$. De esta forma, ha señalado uno de los principales especialistas de la política exterior alemana del siglo XX, el profesor Klaus Hildebrand, el año 1930 se habría pasado de una política exterior republicana a una dominada por gabinetes de tipo presidencial y que no contaban con mayoría parlamentaria ${ }^{27}$. Esto implica que quienes representaban al gobierno alemán en Chile en los años que antecedieron inmediatamente a la caída de Ibáñez y en el período de turbulencias que le siguió, eran, en general, políticos de tendencia autoritaria y conservadora, posición que debe tenerse en cuenta a la hora de valorar el contenido de su correspondencia.

\section{De LA INTERVENCIÓN MILITAR \\ A los PRimeros años del gobierno de Carlos IbÁÑez (1924-1930)}

En un telegrama de 6 de septiembre de 1924 el representante del gobierno alemán en Chile, barón von Spee, explicaba las razones de la intervención militar ${ }^{28}$, atribuyéndola a la "gran disconformidad existente con la insostenible situación política y financiera en relación con la aprobación del proyecto de dieta para senadores y diputados, mientras los funcionarios públicos, militares, marinos permanecía hace meses impagos" ${ }^{29}$.

Llama la atención que entre la correspondencia enviada desde Chile al Ministerio de Relaciones Exteriores alemán se incluya una carta fechada en Santiago el 12 de septiembre de 1924 y firmada por Jorge Schneider Labbé ${ }^{30}$, en el que, contra la opinión dominante en la historiografía ${ }^{31}$, y sin que se den mayores fundamentos

\footnotetext{
${ }^{24}$ KolB, Eberhard, Gustav Stresemann (München, Beck, 2003).

${ }^{25}$ PYTA, Wolfram, Hindenburg: Herrschaft zwischen Hohenzollern und Hitler (München, Pantheon, 2009).

${ }^{26}$ Brahm García, Enrique, Hitler y la Segunda Guerra Mundial (Santiago, Editorial Universitaria, 1999), p. 45.

${ }^{27}$ Hildebrand, Klaus, Das vergangene Reich. Deutsche Aussenpolitik von Bismarck bis Hitler (Stuttgart, DVA, 1996), pp. 383 ss.

${ }^{28}$ Cfr. VIAL, Gonzalo, Historia de Chile, cit. (n. 4), III.

${ }^{29}$ Telegrama de 6 de septiembre de 1924, Politisches Archiv des Auswärtigen Amts, Berlín (en adelante PAAA), R 79091.

${ }^{30}$ Autor de Crédito Popular (Santiago, 1921) y En el Antiguo Solio Virreinal (Santiago, 1930).

${ }^{31}$ Cfr., por ejemplo lo afirmado por Millar Carvacho, René, Significado y alcances del movimiento militar de 1924, en Memoria Chilena (www.memoriachilena.cl), p. 107, donde se sostiene: "El movimiento de septiembre no fue pensado ni meditado por nadie (el intento de golpe de la oposición no tuvo ninguna relación con éste); basta para afirmarlo el detenerse un momento a reflexionar sobre el desarrollo de los acontecimientos a partir del 2 de septiembre. No existía un plan previo, ni nada semejante. Sólo había una inquietud de parte de los oficiales
} 
al respecto, se sostiene que la intervención de los militares correspondía a una actuación "perfectamente estudiada y organizada durante cuatro meses"32.

A fines del mes de enero de 1925 se empezaba a informar al gobierno alemán de la nueva intervención militar ${ }^{33}$, que había provocado la caída de la Junta de Gobierno encabezada por el general Altamirano, y de la cual el representante germano tenía en general una buena opinión ${ }^{34}$, dando cómo razones el creciente poder que habría ido adquiriendo la Junta Militar ${ }^{35}$ y las relaciones cada vez más estrechas que habría tenido la Junta de Gobierno con personeros de la Unión $\mathrm{Naciona}^{36}$. En todo caso le merecían dudas los rumores que circulaban en orden a que se llamaría de vuelta al ex presidente Arturo Alessandri ${ }^{37}$.

Respecto al nuevo gobierno, cuyo hombre fuerte seguiría siendo Carlos Ibáñez, la diplomacia alemana tenía una opinión positiva. Luego de destacar la gran cantidad de decretos leyes que se habían dictado en pocos meses, señalaba que en la mayoría de ellos era posible encontrar un "núcleo muy sano" 38 . Sin duda se estimaba como positivo, desde la perspectiva de un país más adelantado

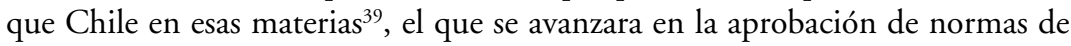
contenido social. Probablemente ello explica el que se enviara a Alemania copia de una entrevista hecha a José Santos Salas, ministro de Higiene, Asistencia, Previsión Social y Trabajo del nuevo gobierno por La Prensa de Buenos Aires, en la que, entre otras cosas explicaba que la creación de su ministerio se debía a que se había comprendido que "por este camino podría llegarse a las grandes conquistas del socialismo de Estado" 40 .

En cambio tenía una opinión más crítica del gobierno de Emiliano Figueroa, con el cual se había estrenado la nueva institucionalidad contenida en la Constitución Política de 1925, y del sistema de partidos dominante todavía en Chile ${ }^{41}$. En un informe de la Legación alemana de 17 de julio de 1926 se señalaba que "las confusas relaciones de los partidos políticos chilenos en el Parlamento han impedido en los últimos años el desarrollo de todo trabajo legislativo de utilidad

jóvenes por su situación profesional y económica, y un profundo desagrado por la aprobación que iban a hacer los parlamentarios de un proyecto en su exclusivo beneficio, cuando a ellos se le negaban los fondos para un aumento de sueldos”.

${ }^{32}$ Carta de Jorge Schneider Labbé de 12 de septiembre de 1924, PAAA R 79091.

${ }^{33}$ Cfr. VIAL, Gonzalo, Historia de Chile, cit (n. 4), III.

${ }^{34}$ En telegrama de 25 de enero de 1925 (PAAA R79091), el barón von Spee afirmaba que la Junta había desarrollado un valioso trabajo en materias de reorganización administrativa y financiera..

${ }^{35}$ Informe de 26 de enero de 1925, PAAA R79091.

${ }^{36}$ Carta de 28 de enero de 1925, PAAA R79091.

${ }^{37}$ Informe de 26 de enero de 1925, PAAA R79091. Donde se afirma que, "en general, los militares no querían a Alessandri”.

${ }^{38}$ Carta de 21 de agosto de 1925, PAAA R79091.

${ }^{39}$ Eichenhofer, Eberhard, Geschichte des Sozialstaats in Europa (München, Beck, 2007).

${ }^{40}$ La Prensa de Buenos Aires de 7 de marzo de 1925, en PAAA R79091. En el mismo sentido se acompañaba un artículo de Carlos Keller, fechado en Concepción el 15 de marzo y publicado en alemán, en que se señalaba que "el nuevo gobierno se apoya fundamentalmente en los partidos de izquierda”, en PAAA R79091.

${ }^{41}$ Para éste puede verse VIAL, Gonzalo, Historia de Chile, cit. (n. 6), Volumen IV. 
y tuvieron por consecuencia, junto con los continuos cambios ministeriales, la corrupción financiera y administrativa. Para eliminar ese cáncer la nueva Constitución, aprobada mediante plebiscito, introdujo una cláusula según la cual los ministros son de exclusiva confianza del presidente. Esta disposición y la reducción de las atribuciones del Senado explican el hecho de que en la nueva Constitución el parlamento aparece debilitado dentro de la división de poderes". Pese a estos cambios $^{42}$, llamaba la atención el representante del gobierno alemán, el sistema seguía sin funcionar. De hecho, después de cuatro meses de sesiones se habrían publicado en el Diario Oficial "sólo 3-4 leyes insignificantes”. Más todavía, se seguía intentando mantener a los ministros bajo el control de las Cámaras ${ }^{43}$.

De ahí que en un despacho posterior, del mes de noviembre del año 1926, la diplomacia alemana empezara a centrarse en el coronel Carlos Ibáñez, al que consideraba la principal figura de los "golpes" ("Putsche") de 5 de septiembre y 23 de enero. Insistiendo en la idea de que había parlamentarios que con su actuación intentaban deformar el funcionamiento del sistema presidencial recién adoptado ${ }^{44}$, se afirmaba: "Lo que sucede en Chile hoy día es una lucha constante del parlamento por recuperar la posición que perdió luego de los dos golpes militares. El partido contrario en esa lucha está formado por los militares bajo el ministro de Guerra Ibáñez, a los que se une, aunque no de una forma incondicional, la marina" ${ }^{45}$. La Legación alemana veía que la situación era tan tensa -esto a propósito de la conformación de un nuevo ministerio encabezado por Manuel Rivas Vicuña- que se sentía obligada a comunicar a su gobierno que hacia el 20 de noviembre podía esperarse un nuevo golpe militar que estableciera la "dictadura" de Ibáñez ${ }^{46}$.

No sería necesario llegar a una nueva intervención militar. Sólo habría una nueva crisis ministerial que terminaría por poner a la cabeza del gabinete, cómo ministro del Interior del gobierno de Emiliano Figueroa, al coronel Carlos Ibáñez ${ }^{47}$. En opinión del representante alemán en Chile, "el nuevo ministerio significa un giro a la izquierda, con el objetivo de hacer realidad las reformas de los últimos años y, al mismo tiempo, el reconocimiento de que la situación excepcional en que se vive no puede enfrentarse con un estricto apego a las leyes; de esta forma se vive una situación similar a una dictadura" ${ }^{38}$. Esta última apreciación se vería

\footnotetext{
${ }^{42}$ Para los cambios sufridos por el régimen de gobierno chileno con la entrada en vigencia de la Constitución Política de 1925 puede consultarse, Brahm - Bertelsen - Amunátegui, cit. (n. 2).

${ }^{43}$ Informe de 17 de julio de 1926, en PAAA 79091.

${ }^{44} \mathrm{Cfr}$. Donoso LeTELIER, Crescente, Notas sobre el origen, acatamiento y desgaste del régimen presidencial. 1925-1973, en, Historia, 13 (Santiago, 1976).

${ }^{45}$ Informe de noviembre de 1926, en PAAA R79091.

${ }^{46}$ Ibíd.

${ }^{47}$ VIAL, Gonzalo, Historia de Chile, cit. (n. 6), IV.

${ }^{48}$ Informe de 27 de febrero de 1927, en PAAA R79091. En este contexto se acompañaba también un recorte de un periódico chileno-alemán de fecha 16 de febrero en el que, entre otras cosas, se sostenía lo siguiente: "Ya en ocasiones anteriores en las que se ha intentado limitar los poderes del parlamento, se ha sostenido, que estos enfrentamientos políticos estarían marcados por la contraposición entre el fascismo y el liberalismo. Sin embargo es bastante dudoso de que en Chile verdaderamente sea posible encontrar un movimiento popular que esté detrás de la
} 
confirmada una vez que Ibáñez asumiera la Vicepresidencia de la República. "En verdad, el gobierno procede de una manera dictatorial, aunque se procure guardar las formas legales" ${ }^{49}$. Finalmente, al informar la elección de Carlos Ibáñez como presidente de la República ${ }^{50}$ el barón von Spee hacía ver que pese a las cada vez más frecuentes arbitrariedades del gobierno, lo que habría generado críticas de parte de los sectores más pudientes de la sociedad, el gobernante contaba con un gran apoyo; además habría mejorado la situación económica ${ }^{51}$.

A esas alturas, los cambios revolucionarios que estaban ocurriendo en Chile a partir del momento en que tuvo lugar la intervención militar de 1924, sólo parecían preocupar a la diplomacia alemana en dos aspectos. Por una parte, y desde el momento en que esto podía dificultar la expansión de la presencia económica de Alemania en Chile, criticaba el excesivo nacionalismo económico que se estaría poniendo de manifiesto en la abundantísima legislación que había entrado en vigencia en esos años ${ }^{52}$. Por otra, temía las repercusiones que podían tener en el orden interior del país los brotes huelguísticos que se estaban dando sobre todo en las pampas nortinas y que era probable terminaran con derramamiento de sangre, detrás de los cuales veía la influencia comunista. "También parece amenazador, escribía el cónsul general de Alemania en Chile, el que no se pueda contar con seguridad con los militares: el regimiento Esmeralda estacionado en Antofagasta parece estar totalmente contaminado con el comunismo y las tropas enviadas a la pampa han terminado por confraternizar con los trabajadores jugando al fútbol"53.

Durante los años siguientes, los primeros de la presidencia Ibáñez, la legación alemana se expresaría siempre en términos positivos en relación a los logros del gobierno. Dejando algo en sordina su carácter semi-dictatorial y las arbitrariedades que le atribuía la oposición, destacaría siempre su carácter realizador. Por ejemplo, al enviar a Alemania una nota que contenía un resumen del discurso con el cual el presidente Ibáñez, que no concurrió personalmente al acto por encontrarse enfermo, inauguraba las sesiones del congreso el 21 de mayo de 1928, el representante alemán señalaba a manera de introducción: "Se trata simplemente de una cuenta objetiva relativa a la extraordinaria y múltiple acción del gobierno" 54 .

figura de Ibáñez, aunque sin duda los ejemplos de Mussolini y sobre todo de Primo de Rivera han influido fuertemente en el dictador", por lo que no puede decirse que lo que está ocurriendo en Chile sea un enfrentamiento político tradicional, en PAAA R79091.

${ }^{49}$ Telegrama de 9 de abril de 1927, en PAAA R79091.

${ }^{50}$ NunN, Frederick M., cit. (n. 6).

${ }^{51}$ Telegrama de 18 de julio de 1927, en PAAA R79105.

${ }^{52}$ Informes del Cónsul General de Alemania en Chile, Valparaíso, de 18 de marzo de 1927 y de 14 de junio de 1927, en PAAA R79091.

${ }^{53}$ Informe del Cónsul General de Alemania en Chile de 16 de mayo de 1925, en PAAA R79091.

${ }^{54}$ Informe de 23 de mayo de 1928, en PAAA R79091. En la cuenta del año siguiente el representante alemán destacaba otra vez el hecho de que el Presidente Ibáñez no se hubiera presentado personalmente ante el congreso para leer su mensaje, lo que atribuía al interés del gobernante dictatorial por manifestar su desprecio hacia el parlamento. Informe de 27 de junio de 1929, en PAAA R79091. 
Favorecía también la buena opinión que se habían formado los diplomáticos de la República de Weimar del gobierno de Ibáñez, el hecho de que este no ocultara sus simpatías por Alemania. Por ejemplo, a comienzos del año 1929 visitó Chile un alto oficial del Ejército alemán, el general Heye. A propósito de esta visita el representante alemán, Olshausen, destacaba que los honores al ilustre militar germano no habían quedado reducidos al estamento militar, sino que le había cabido también una participación importante al mismo presidente de la República. "Ibáñez no se conformó con recibir al general Heye en audiencia oficial, sino que aprovechó la oportunidad de encontrarse varias veces con él, antes de que éste llegara a Santiago (había estado de visita en el sur del país) en el campo de maniobras", donde además el único representante de gobiernos extranjeros lo era el mismo Olshausen ${ }^{55}$.

Esta buena impresión que se tenía del gobierno de Ibáñez tampoco variaría luego del importante cambio de gabinete que tuvo lugar a mediados del año 1929 y que significaría la salida de dos de los principales pilares en que se habían apoyado las grandes reformas introducidas por Carlos Ibáñez: Pablo Ramírez y Conrado Ríos. En opinión de la Legación alemana el cambio no debería significar ninguna variación importante en el curso de la política chilena, porque este se explicaría sólo en problemas personales entre los ministros y el presidente de la República ${ }^{56}$. Habría habido un choque entre Ramírez y Ríos. A ello habría que agregar el hecho de que "ambos eran personalidades muy temperamentales que habían sido bienvenidos en los primeros años de gobierno en su calidad de "escobas de acero", pero que a la larga y en épocas más tranquilas de consolidación no se habían mostrado como funcionarios particularmente dotados en materias administrativas y de organización, y que además habrían tomado una serie de decisiones en materias de personal particularmente duras que habían generado críticas de las cámaras y el surgimiento de una serie de animosidades personales" 57 .

La verdad es que el representante alemán tenía una mejor opinión de Ibáñez que de sus más inmediatos colaboradores. Particularmente crítica era su caracterización del ministro de Hacienda, que ahora dejaba el cargo, Pablo Ramírez. "El ministro de Hacienda Ramírez no desmiente en el tipo de su pequeño cráneo y en todos sus hábitos corporales la fuerte mezcla indígena de su sangre, que le viene, supuestamente, por el lado materno. Se trata de un individuo muy inteligente, enérgico, rápido para tomar decisiones y algo brutal, cuyas capacidades lo transformaron en el hombre de confianza del presidente y lo pusieron a la cabeza del gabinete", pero que por su mismo carácter fuerte habría empezado a tener una serie de roces tanto con Ibáñez cómo con el ministro de Relaciones Exteriores Conrado Ríos ${ }^{58}$.

${ }^{55}$ Informe de 1 de abril de 1929, en PAAA R79069. Más adelante, comentando una gira por Europa que realizaba Conrado Ríos Gallardo, destacaba el que éste hubiera afirmado que la nación europea que más le había impresionado era Alemania. Informe de 28 de mayo de 1930, en PAAA R79106.

${ }^{56}$ Telegrama de 23 de agosto de 1929, en PAAA R79091.

${ }^{57}$ Informe de 19 de septiembre de 1929, en PAAA R79091.

${ }^{58}$ Informe de 14 de marzo de 1929, en PAAA R79106. Más adelante, en un informe de 
De ahí que los cambios impulsados por Ibáñez habrían apuntado a dar responsabilidades de gobierno, en reemplazo de los "hombres nuevos" con los que había iniciado su gobierno, pero que de alguna manera contrastaban por su estilo y hábitos morales y su baja extracción social, con la dirigencia tradicional del país, a representantes de la aristocracia ${ }^{59}$.

El 20 de febrero de 1930 el jefe de la legación alemana en Chile, Dr. Olshausen, hacía un balance de lo que había sido el gobierno de Ibáñez cuándo este se acercaba a la mitad de su período presidencial. En su opinión, y pese a que a esas alturas ya se había desencadenado a nivel mundial la "gran depresión" del año 1929, "la situación del gobierno del presidente Ibáñez debe considerarse pese a todo cómo firme e inquebrantable". El diplomático alemán estimaba que ello era así pese a que éste mostraba una serie de debilidades que en determinadas circunstancias podrían llegar a ser peligrosas, aunque creía que los críticos más duros del gobierno, cómo lo eran los políticos desplazados del poder, no tenían ninguna posibilidad de recuperarlo. "Por el contrario parecen dignas de atención las aprehensiones manifestadas por sectores más moderados y prudentes, y que lo único que quieren es el bien del estado y que ven con preocupación algunas medidas del actual gobierno. Estos reprochan al gobierno, no sin razón, que la inmensa cantidad de proyectos que éste ha emprendido superan por lejos los recursos del país. Además muchos de estos trabajos serían superfluos y servirían únicamente a la necesidad del gobierno de mostrar una serie de logros materiales para así asegurarse el aplauso de las masas. Otros proyectos, pese a su indudable importancia, habrían sido emprendidos de manera apresurada y sin la debida preparación. Este sería el caso de una serie de reformas en el ámbito de las obras públicas y de la educación. Estos errores habrían costado al estado una gran cantidad de dinero, los que se habrían financiado con constantes alzas de los impuestos encareciendo el coste de la vida, y habrían dejado al estado fuertemente endeudado y dependiente del extranjero", problemas que se podrían haber evitado si el gobierno hubiera actuado con algo más de prudencia.

Sin perjuicio de reconocer la validez de esas críticas y las debilidades que manifestaba el nuevo régimen, Olshausen concluía que "el actual gobierno tenía fundamentos más sólidos que la mayoría de los que le antecedieron. El mejor y más fuerte fundamento del actual sistema es la persona misma del Presidente, al que si bien le faltan las condiciones de un estadista genial, puede congratularse de gozar de un gran prestigio por su fortaleza, y su absoluta limpieza e incorruptibilidad en el más amplio sentido de la expresión. Tras años de inseguridad, de una inaudita corrupción y arbitrariedad en todas las ramas de la administración, ha conseguido restablecer la tranquilidad, el orden y la seguridad y con ello se ha sabido ganar la simpatía incluso de aquellos círculos que hoy día ya no conducen el país, pero que han mantenido sus posesiones y se han beneficiado de la favorable

7 de julio de 1931 (PAAA R79106), se insistía en la fuerte personalidad de Ramírez y en sus problemas morales. Respecto a Ríos Gallardo, cfr. nota de 30 de noviembre de 1929, en PAAA R79106.

${ }^{59}$ Informe de 19 de septiembre de 1929, en PAAA R79091. Cfr. informe de 19 de noviembre de 1929, en PAAA R79106. 
coyuntura económica. Además debe reconocerse que hoy día, pese a los ripios del programa de reformas, se está desarrollando un trabajo serio para sacar al país de su atraso y transformarlo en un estado progresista y moderno".

Con todos estos antecedentes la conclusión a la que llegaba el representante alemán cuando se iniciaba el año 1930 era que "el gobierno dirigido por el presidente Ibáñez lo más probable es que en un tiempo razonable se vea libre de todo tipo de conmociones que pongan su existencia en peligro"60.

En todo caso, en el plano político, Olshausen destacaba el hecho de que bajo el régimen dictatorial que se vivía, languidecía la vida de los partidos ${ }^{61}$, lo que se vería muy luego confirmado por las parlamentarias de 1930 que se hicieron sin competencia y resultaron de un acuerdo entre el gobierno y las directivas partidistas ${ }^{62}$. "El nuevo congreso, afirmaba, debería ser un instrumento todavía más dócil y sin voluntad propia que sus antecesores. No es más que un órgano consultivo del gobierno" 63 .

\section{SE PRECIPITA LA CRISIS (1930-1931)}

Poco a poco se empezarían a sentir los efectos de la crisis económica mundial en Chile, con su consiguiente repercusión sobre la estabilidad del gobierno. En un telegrama de 12 de agosto de 1930 el representante alemán comunicaba al Ministerio de Relaciones Exteriores en Berlín, la disconformidad que había con las medidas de ahorro que había decretado el gobierno y sobre todo con la reducción de los sueldos, lo que habría servido para que los sectores opositores a Ibáñez iniciaran una política de agitación. Ello habría provocado una serie de protestas estudiantiles, "de acuerdo al modelo boliviano", que el gobierno habría reprimido a través de carabineros. Ello habría provocado un cambio ministerial en el que se destacaba el ingreso como ministro de Hacienda y hombre fuerte y con un drástico plan de ahorros del ciudadano de origen alemán Julio Philippi ${ }^{64}$ y del almirante Carlos Froedden como ministro del Interior. Pese a que este último era de origen danés, la oposición hablaría de un "gabinete alemán" ${ }^{65}$.

En principio, en la perspectiva alemana, el nuevo gabinete se interpretaba como un reforzamiento del elemento militar en el gobierno y cómo el intento de superar los desencuentros que se habían dado entre el ejército y la marina ${ }^{66}$. Con algo más de distancia se argumentaría luego que el hecho de que un marino pasara a ser ministro del Interior sería una prueba de la creciente influencia de esa

${ }^{60}$ Informe de 20 de febrero de 1930, en PAAA R79091.

${ }^{61}$ Ibíd.

${ }^{62}$ Se trata del así llamado "Congreso Termal” (el "cuoteo" entre los partidos se había concretado en las Termas de Chillán). Cfr. Silva - Silva - Villalobos - Estellé, cit. (n. 6), IV, p. 923.

${ }^{63}$ Informe de 7 de junio de 1930, en PAAA R79091.

${ }^{64}$ Una caracterización de Philippi se encuentra en PAAA R79069. Para la familia Philippi puede consultarse la biografía de su hijo homónimo, Millar CARVACHO, René, Pasión de servicio. Julio Philippi Izquierdo (Santiago, Ediciones Universidad Católica de Chile, 2005).

${ }^{65}$ Telegrama de 12 de agosto de 1930, en PAAA R79091.

${ }^{66}$ Informe de 19 de agosto de 1930, en PAAA R79091. 
rama de la Defensa Nacional derivada del hecho de que el tratado con Perú de $1929{ }^{67}$ permitía descartar una posible guerra con ese país, con lo que el Ejército parecía perder algo de su importancia. En cambio para el prestigio exterior de Chile y para el desarrollo de su comercio, era de mayor importancia contar con una gran flota de guerra. En todo caso la conclusión del diplomático alemán era que los acontecimientos de las últimas semanas debían interpretarse como un reforzamiento del régimen ibañista ${ }^{68}$. Esto pese a que a la situación seguía complicándose y que los gabinetes se hacían cada vez más inestables. Ya en enero de 1931 debía lamentar el agente alemán la caída del ministro de Hacienda Julio Philippi, la que se explicaría no sólo por la diferencias que habrían surgido entre éste y los demás ministros, sobre todo los representantes de las fuerzas armadas, en relación al estricto programa de ahorros que impulsaba, sino también en el hecho de que Philippi "habría querido poner freno a una serie de negociados ilegales de políticos influyentes"; también habría jugado en contra de la permanencia en el ministerio del ministro de origen germano algunas diferencias con el ex ministro Pablo Ramírez, de quién Ibáñez estaría preparando el regreso al gobierno ${ }^{69}$.

Pese a los evidentes síntomas de inestabilidad que menudeaban - protestas estudiantiles, creciente activismo político que se movilizaba contra los programas de ahorro y hasta intentos fracasados de golpe de Estado ${ }^{70}$ - el representante del gobierno alemán, todavía en el mes de abril de 1931, seguía creyendo en la fortaleza del gobierno de Ibáñez. "Nuestra afirmación contenida en el informe relativo al año 1929, en el sentido de que la situación del gobierno del presidente Ibáñez podía considerarse como bastante firme, ha quedado confirmada para el año recién pasado. El general Ibáñez ha podido controlar de raíz tanto los desórdenes provocados por los estudiantes, inficionados por la sicosis revolucionaria sudamericana del último año, cómo también el "Putsch" de algunos jóvenes y ambiciosos oficiales que apoyaron al conocido revolucionario chileno y líder de los deportados, coronel Marmaduque Grove, cuándo éste aterrizó en Concepción el 21 de septiembre de $1930^{71}$. Ha quedado demostrado que aquellos tercos y eternos descontentos y aquellos que fueron en su momento desplazados de sus posiciones de poder", no han logrado superar sus diferencias y hacer un frente común. "De esta forma los militares, que desde hace una serie de años han asumido la conducción política y la responsabilidad, no tienen frente a ellos ningún enemigo político interno dotado de medios de poder"72.

La positiva visión que se tenía del gobierno de Ibáñez por parte de la diplomacia alemana no variaría en lo fundamental en los meses siguientes, pese a la agudización de la crisis económica y a que se acentuaba la inestabilidad de los gabinetes

${ }^{67}$ Cfr. Barros, Mario, Historia diplomática de Chile (1511-1938) (Barcelona, Ediciones Ariel, 1970), pp. 707ss.

${ }^{68}$ Informe de 29 de agosto de 1930, en PAAA R79091.

${ }^{69}$ Informe de 25 de enero de 1931, en PAAA R79106. Se hacía ver al respecto que el sucesor de Philippi, Carlos Castro Ruiz, era un "Intimus" de Ramírez.

${ }^{70}$ Cfr. VIAL, Gonzalo, Historia de Chile, cit. (n. 6), IV.

${ }^{71}$ Cfr. Vial, Gonzalo, Historia de Chile, cit. (n. 6), IV, pp. 505 ss.

${ }^{72}$ Informe de 15 de abril de 1931, en PAAA R79093. 
ibañistas. En efecto, a fines del mes de abril tenía lugar un nuevo e importante cambio ministerial ${ }^{73}$. Al respecto el Dr. Olshausen opinaba que este tenía su origen en razones personales y no de fondo y que el cambio mostraba "que el presidente Ibáñez sigue buscando a tientas hombres que lo entiendan y apoyen en sus esfuerzos por conducir de forma honrada y fuerte el destino de Chile hacia su verdadero y general bien común. Lamentablemente las principales dificultades para rodearse con colaboradores fieles y de valor y al mismo tiempo mantener el contacto con los círculos más poderosos en lo económico y social de la así llamada "sociedad" están en la historia de su propio ascenso. Es sintomático que hayan dejado otra vez el gabinete precisamente los representantes de esos sectores"74.

Más allá de lo anterior, la conclusión a la que llegaba el representante alemán, era "que si bien la posición de Ibáñez desde el punto de vista político seguía siendo sólida debido al apoyo con que contaba en el ejército, la marina, carabineros y la fuerza aérea, los necesarios programas de ahorro que había debido implementar como consecuencia de la crisis económica mundial" podría ocasionarle algunos problemas incluso al interior de esos pilares de su régimen. "Será tarea del presidente impulsar con el apoyo de todos los sectores una exitosa solución de los problemas financieros y económicos" 75 .

Pero el deterioro de la situación económica y por ende de la política iba mucho más rápido que lo que nadie hubiera podido imaginar, de tal forma que apenas unos días después del despacho antes citado, Olshausen enviaba un mensaje cifrado a su gobierno en el que señalaba que el estado chileno estaba prácticamente en bancarrota, que no podía ni siquiera pagar los sueldos de la administración, lo que contribuía a resentir la fidelidad de las mismas fuerzas armadas al primer mandatario. Agregaba, además, que el presidente estaría mostrando síntomas de inseguridad y de debilidad en la conformación de su equipo de gobierno; los cambios ministeriales se sucedían con rapidez e Ibáñez no encontraba los hombres adecuados que lo ayudaran a superar la crisis. Su conclusión era que la situación parecía bastante más difícil de lo que había informado hasta entonces, por lo que, "si bien no era previsible que se produjera en lo inmediato la caída del gobernante, dudo que Ibáñez pueda mantenerse en el poder hasta el final del año"76.

Por último, ya en el mes de julio el extremo agudizamiento de la crisis lo llevaba a opinar que, pese a los esfuerzos del Presidente, "se consolidaba la opinión de que su gobierno se acercaba a su fin”. Y a ello se agregaba la presencia de Arturo Alessandri en Buenos Aires, quien podría aliarse con otros enemigos de don Carlos para derrocarlo. Pero todavía veía como posible que el gobierno consiguiera una asesoría financiera de expertos americanos o ingleses que consiguiera introducir reformas en ese plano que no afectaran demasiado los sueldos de los uniformados, con lo que su posición podría otra vez salir fortalecida ${ }^{77}$. Nada de

${ }^{73}$ Cfr. Valencia Avaria, Luis, Anales de la República (2a edición, Santiago, Editorial Andrés Bello, 1986), I, p. 582.

${ }^{74}$ Informe de 6 de mayo de 1931, en PAAA R79106.

${ }^{75} \mathrm{Ibid}$.

${ }^{76}$ Informe de 16 de mayo de 1931, en PAAA R79093.

${ }^{77}$ Informe de 8 de julio de 1931, en PAAA R79093. Cfr. informe de 22 de julio de 1931 
lo anterior resultó, pero sí Ibáñez se vio forzado a impulsar un nuevo cambio de gabinete -Juan Esteban Montero en Interior y Pedro Blanquier en Hacienda ${ }^{78}$-, clara manifestación de debilidad del gobernante desde el momento en que, en opinión de Olshausen, cómo en los tiempos del parlamentarismo los ministros no habrían sido designados directamente por el Presidente, sino que habría sido Blanquier el que dio forma al gabinete. Más todavía, en él otra vez aparecían representados los partidos políticos y la antigua aristocracia. Todo ello sería una muestra evidente de la "difícil situación de Ibáñez"79.

Finalmente, a través de un telegrama de fecha 27 de julio de 1931 la legación alemana en Chile informaba a su gobierno que el presidente de la República Carlos Ibáñez del Campo, después de un par de días de desórdenes, había presentado su renuncia ${ }^{80}$. A la semana siguiente el Dr. Olshausen, en una carta al Ministerio de Relaciones Exteriores de su país, trataba de explicar las razones que estaban detrás del derrumbe de un régimen que hasta hacía sólo unos pocos meses, le parecía tan sólido. En su opinión, en los últimos meses la situación se había hecho cada vez más inmanejable por la profundización de la crisis económica y la propaganda desarrollada por los rivales de Ibáñez. Por un momento pareció que con el ministerio Montero-Blanquier, en el que se mezclaban la dinámica de la juventud militar y la experiencia de las antiguas y tradicionales familias chilenas, se habría alcanzado la estabilidad. "Pero cuando Ibáñez despidió también ese gabinete ante el temor de que los estrictos recortes presupuestarios exigidos por Blanquier, implicaran sacrificar el sueldo de los Carabineros y con éste de su base de poder, comenzó el colapso”.

En todo caso el último impulso habría provenido "de la actitud adoptada por la juventud estudiantil, perteneciente en su mayor parte a la antigua oligarquía; o mejor dicho, de la movilización de la opinión pública contra los carabineros", provocada por algunos enfrentamientos entre estos y los sectores académicos, tanto profesores como estudiantes, que derivó en violentos enfrentamientos en el centro de la capital, como consecuencia de los cuales hubo algunos muertos.

Según Olshausen, era probable "que pese a todo el presidente se hubiere podido sostener en el poder, si él hubiera querido aceptar la prueba de fuerza; aparentemente ni los carabineros ni el mismo ejército regular le habrían negado su obediencia. Pero el mismo tuvo finalmente que reconocer que su renuncia resultaba inevitable si se quería impedir un mayor derramamiento de sangre y lograr una pacificación general; más todavía, que en vista de lo turbulento de la situación el crédito del país seguiría bajando y una vez que se hubiera agotado totalmente la caja fiscal perdería a sus últimos fieles" ${ }^{\prime 1}$.

De esta forma el enviado alemán terminaba por destacar una serie de elementos que realzaban la figura de Ibáñez al momento de su renuncia al poder, tal cual ha

en que se volvía insistir en que la única salida de Ibáñez era que tomaran el control del país los americanos, "que de hecho ya gobernaban todo a través de la Cosach", en PAAA R79093.

${ }^{78}$ Valencia AVARIa, cit. (n. 73), I, p. 582.

${ }^{79}$ Informe de 15 de julio de 1931, en PAAA R79093.

${ }^{80}$ Telegrama de 27 de julio de 1931, en PAAA R79093.

${ }^{81}$ Informe de 6 de agosto de 1931, en PAAA R79105. 
hecho parte de la historiografía citada en la Introducción. Pese a disponer todavía de importantes apoyos, no quiso aferrarse al poder a cualquier precio para evitar males mayores a la población y al país. De ahí que no pueda extrañar el que en un balance final Olshausen hiciera una caracterización en general positiva de la figura de Ibáñez, tanto en lo personal como en su calidad de gobernante. "Ibáñez no fue ningún tirano, afirmaba el diplomático alemán, pese a ciertas palabras duras y llenas de odiosidad por las que se había dejado llevar el pueblo en medio de los desórdenes. El fue un oficial simple y que creció en medio de las limitaciones de la vida de provincia, el que fuera de sus años de instructor militar en Colombia (en realidad debió decir El Salvador), nunca pudo mirar más allá de los límites de su país, al que faltaba todo conocimiento universal, y que pese a una cierta dosis de conocimiento de los hombres, tampoco gozaba de los supuestos sicológicos cómo para juzgar a los demás. Mirado en menos por las así llamadas familias aristocráticas por su baja extracción social y su profesión militar, se relacionaba sólo con un relativamente pequeño círculo de camaradas militares, fieles, no muy decentes y de limitada formación. Pese a todo, gente recta, incluso perteneciente a aquellos círculos que Ibáñez tanto combatió, nunca desconocieron su calidad de gran patriota, su honradez personal y la forma enérgica en que buscaba el bien del país" 82 .

Destacaba también el representante de la República de Weimar que Ibáñez había llegado al poder en un momento de gran desorden económico y en el que el país seguía dominado por la antigua oligarquía, por lo que las mayorías anhelaban un hombre fuerte que pudiera introducir profundas reformas en todos los ámbitos de la vida nacional. Su error habría estado en que sus ambiciosos planes excedían a las posibilidades financieras del país y en que lo habrían acompañado en el gobierno algunas figuras de dudosa calidad moral. Pese a todo, con algo más de suerte y un clima internacional más favorable -sostenía Olshausen- Ibáñez pudo haber completado su período presidencial y haber dejado el poder cómo "uno de los más grandes presidentes" de Chile. Esto es "como aquel que, desde una cierta perspectiva, introdujo verdaderamente el orden y la disciplina; cómo aquel que en materias de política interna terminó con los abusos de los partidos, que desplazó a la en parte corrupta oligarquía, que en materia de política exterior puso fin al antiguo conflicto con Perú, que en contraste con los últimos presidentes de todos los estados vecinos se mantuvo incorruptible en lo personal $\mathrm{y}$, fundamentalmente, que puso una barrera a la amenaza comunista que había tomado fuerza bajo el mandato del anterior demagogo, el presidente Alessandri. Así como están las cosas hoy en día sólo se escuchan críticas desde todos los sectores: la disciplina se llama ahora tiranía, el acuerdo con Perú alta traición, el extrañamiento de Alessandri se considera como una ofensa a un popular amigo del pueblo, los límites impuestos al funcionamiento del sistema de partidos cómo represión de la libertad y en cuanto a la honradez personal ella aquí no cuenta

${ }^{82}$ Informe de 6 de agosto de 1931, en PAAA R79105. 
mucho: trágico destino de un "Kondottiere" americano; pero está por verse si esto significará el fin de su carrera" ${ }^{83}$.

\section{LOS PRIMEROS INTENTOS POR RECUPERAR EL PODER (1931-1932)}

Cómo bien se sabe, la caída de Ibáñez no resolvió los problemas del país, el que se encontraba sumido en una crisis muy profunda. Ello explica que en los meses siguientes se viviera un período de gran inestabilidad política -la "segunda" anarquía- que recién se empezaría a superar con la elección de Arturo Alessandri como presidente de la República a fines del año 1932. En ese ambiente de generalizado desorden marcado por el marasmo económico, la cesantía y el actuar cada vez más autónomo de las distintas unidades militares, se mantuvo latente la posibilidad de que Carlos Ibáñez recuperara el poder. El mismo general, exiliado de momento en Argentina, y sus partidarios en Chile, serían actores claves de la política chilena durante esos meses de gran convulsión ${ }^{84}$. Por lo menos esa es la opinión que manifestaría de forma constante el representante del gobierno alemán en Chile, el que, al parecer, no veía con malos ojos la vuelta al poder del "dictador". Y esto porque, curiosamente, el gran temor de la diplomacia alemana, era que llegara a la presidencia de la república Arturo Alessandri, a quién se calificaba de "peligroso" y de "demagogo comunista" ${ }^{55}$. De ahí que en las elecciones que enfrentaron a éste con Juan Esteban Montero ${ }^{86}$ se mostraran partidarios del último ministro del Interior de Ibáñez, pese a que dudaban de que tuviera la personalidad adecuada como para enfrentar los graves problemas por los que atravesaba Chile ${ }^{87}$. Por lo demás y como es natural, ya una vez como presidente de la República, éste buscaría con rapidez desprenderse de la herencia ibañista ${ }^{88}$.

Más todavía, la situación de inestabilidad se agravaba -y el enviado alemán no daba al nuevo gobierno más de 6 meses de vida- desde el momento en que, en su común oposición al presidente Montero, estaban actuando momentáneamente

${ }^{83}$ Ibid. Por último Olshausen insistía en la creciente influencia que estaban adquiriendo los Estados Unidos en Chile, lo que era siempre una de sus principales preocupaciones. "En el curso de los últimos doce meses Chile ha pasado a ser una provincia del país de la bandera estrellada”.

${ }^{84}$ Cfr. Vial, Gonzalo, Historia de Chile (1891-1973) (Santiago, Editorial Zig-Zag, 2001), V: De la República Socialista al Frente Popular 1931-1938

${ }^{85}$ Telegrama de 2 de octubre de 1931, en PAAA R79105 e Informe de 25 de agosto de 1931, en PAAA R 79106.

${ }^{86}$ VIAL, Gonzalo, Las elecciones presidenciales de 1931 y 1932. El retorno del León, en Camino a La Moneda, cit. (n. 5), pp. 117 ss.

${ }^{87}$ Informe de 25 de agosto de 1931, en PAAAR 79106 y telegrama de 5 de octubre de 1931, en PAAA R79093.

${ }^{88}$ Así despediría de inmediato al "más odiado" de los partidarios de Ibáñez, Pablo Ramírez, que se encontraba de representante chileno en París; lo mismo ocurriría con Conrado Ríos Gallardo que se encontraba en Lima, quien había enviado un telegrama a Ibáñez en que lo animaba a reprimir con mano dura las protestas y con el embajador en Estados Unidos, Carlos Dávila, "quien al momento de la revolución de julio se encontraba viajando de Washington a Santiago porque Ibáñez le habría ofrecido el Ministerio de Relaciones Exteriores o el del Interior”. Informe de 20 de octubre de 1931, en PAAA R79106. 
unidos los partidarios de Ibáñez y los de Alessandri ${ }^{89}$. Y la situación se hizo todavía más crítica cuando la prensa empezó a anunciar que Carlos Ibáñez había viajado de Buenos Aires a Mendoza, preparando su vuelta a Chile, la que sus más cercanos cómo Dávila y Ríos Gallardo anunciaban para el mes de marzo ${ }^{90}$. Al mismo tiempo algunos periódicos informaban sobre supuestos complots ibañistas e incluso se había detenido por ello "al conocido ibañista" Carlos Dávila"

Todos estos movimientos culminarían el 4 de junio con una nueva intervención militar que derrocaría a Juan Esteban Montero para dar inicio a la llamada "República Socialista", que tendría primero como hombre fuerte a Marmaduque Grove y luego a Carlos Dávila ${ }^{92}$. En esos días de junio no era fácil determinar cuál sería la salida definitiva de la situación, desde el momento en que aparecían combatiendo al nuevo gobierno y enfrentados entre sí tanto los socialistas como los ibáñistas y alessandristas, aunque lo que parecía más seguro era la vuelta al poder de Carlos Ibáñez ${ }^{93}$. En todo caso, en el intertanto se veía con buenos ojos el que se hubiera impuesto la posición más "moderada” de Dávila sobre la más "radical (comunista)" de Grove ${ }^{94}$.

Buscando una explicación de fondo a acontecimientos que se habían desarrollado de manera tan vertiginosa, el representante alemán sostenía que la política moderada del presidente Montero, orientada hacia la clase media, había terminado por fracasar al pasar su gobierno a ser controlado por las familias de la aristocracia tradicional. "Ese estamento agrario-conservador-clerical lo había rodeado de tal forma, que Montero no fue capaz de conseguir que los grandes propietarios aceptaran los necesarios sacrificios económicos", que eran indispensables para enfrentar la crisis. Esta situación de debilidad del gobernante habría sido aprovechada por los ibañistas, "esto es, aquellos representantes de la clase media que bajo la dictadura de Ibáñez habían desempeñado funciones administrativas y por los alessandristas, compuestos por intelectuales de izquierda y por las masas trabajadoras", para terminar por derribarlo. "El líder más activo de los ibañistas, el ex embajador Carlos Dávila, me informó que él había preparado el golpe contra Montero desde el mes de febrero". Pero el mar de fondo de todos estos cambios políticos no sería sólo la catastrófica situación económica y financiera "sino la aceleración del enfrentamiento social entre la pequeña minoría de familias propietarias sin energía y en vías de desaparecer, con la activa clase media, por ella tan despreciada, de origen araucano o de otra sangre no española, de la cual forma parte también la casta mi-

${ }^{89}$ Informe de 18 de noviembre de 1931, en PAAA R79093.

${ }^{90}$ Informe de 28 de enero de 1932, en PAAA R79093.

${ }^{91}$ Informe de 10 de marzo de 1932, en PAAA R 79093. Se acompañaba copia de un artículo del Deutsche Zeitung für Chile de 24 de febrero de 1932, donde se señalaba que se habría querido enviar un avión a Mendoza para trasladar a Chile al general Ibáñez para hacerlo nuevamente Presidente de la República.

${ }^{92}$ Para la República Socialista puede consultarse VIAL, Gonzalo, Historia de Chile, cit. (n. 84), V y en cuanto a las medidas anti propietarias tomadas por los gobiernos de Grove y Dávila, Brahm García, Enrique, Propiedad sin libertad: Chile 1925-1973. Aspectos relevantes en el avance de la legislación socializadora (Santiago, Ediciones Universidad de los Andes, 1999).

${ }^{93}$ Telegramas de 18 de junio de 1932 y de 22 de junio de 1932, en PAAA R79093.

${ }^{94}$ Informe para la semana del 19 al 25 de junio de 1932, en PAAA R79093. 
litar, y la gran masa proletaria, indolente y receptiva de todo tipo de propaganda”. Ello sin perjuicio de que informara también a su gobierno de que había quienes opinaban que los enfrentamientos políticos sólo tendrían su origen en diferencias personales entre los distintos caudillos, planteamiento que parecía no convencerlo, desde el momento en que caracterizaba a los sectores que se disputaban el poder sobre todo por sus características ideológicas. Así es como se refería a "la bandera soviética" de los partidarios de Grove; al "programa socialista" de Alessandri; al “capitalismo de Estado" de Dávila y, lo que resulta más sorprendente, al incipiente "nacionalsocialismo" de algunos oficiales ibañistas".

En todo caso los alemanes seguían pensando en que lo más probable era que la situación se estabilizara recién con la vuelta de Carlos Ibáñez al poder. Ello considerando que los actores fundamentales del proceso revolucionario -la oficialidad del Ejército- estaban en contra de Alessandri y de las masas que lo seguían, difíciles de manejar, y se habían desilusionado tanto del gobierno de Montero, controlado por los grandes propietarios, como del de Dávila. "Pese a todos los desmentidos lo que desea el Ejército es una dictadura militar, y el único general, que probablemente puede contar con el apoyo de la casi totalidad del Ejército y de Carabineros, es don Carlos Ibáñez”. De tal forma que estimaban que la única posibilidad que tenía el ibañista Dávila de conservar el poder, era dando entrada a éste al caudillo del movimiento militar: "la persona del general Ibáñez se levanta cada vez con más fuerza desde la niebla de su destierro" ${ }^{\text {. }}$.

Con todo esto se explica que para el representante alemán, von Reiswitz, la llegada a Chile de Carlos Ibáñez y el inicio de sus negociaciones con Dávila, necesariamente debían terminar con el ingreso del general al gobierno, el que adquiriría de esa forma un carácter más moderado, dejando de lado sus proyectos de reforma "ultrasocialistas" y hasta "bolcheviques"97. Por lo demás el que se hubiera llegado a un gobierno "socialista" no resultaba sorpresivo, porque el socialismo que se había manifestado ya en la revolución del año 1924, había ido tomando cada vez más fuerza y estaba dirigido en lo fundamental contra el dominio de las antiguas familias de la aristocracia ${ }^{98}$.

Para sorpresa del representante alemán, Carlos Ibáñez no consiguió su objetivo de recuperar el gobierno. Sus negociaciones con Dávila no llegaron a puerto. ¿Por qué? "Aparentemente, se señalaba en un detallado informe de la legación alemana relativo a los sucesos revolucionarios que habían tenido lugar en Chile, las tropas

${ }^{95}$ Informe de 23 de junio de 1932, en PAAA R79094. En PAAA R79069 se incluye un recorte de Der Angriff, el diario nacionalsocialista de Berlín, de 12 de septiembre de 1932, con una entrevista al representante chileno en Alemania Luis de Porto Seguro, en cuyo último párrafo el periodista, para destacar las bondades de Chile, señalaba que había sido uno de los pocos países sudamericanos que había mantenido la neutralidad frente a Alemania durante la Primera Guerra Mundial y se felicitaba que ahora - bajo la "República socialista" - tuviera un gobierno "nacionalsocialista".

${ }^{96}$ Informe de 4 de julio de 1932, firmado por von Reiswitz, en PAAA R79094.

${ }^{97}$ Telegrama de 7 de julio de 1932, en PAAA R79094 e Informe de 15 de julio de 1932, en PAAAR79121.

${ }^{98}$ Abschrift zu III MS 3667/32 Die chilenische Revolution im Sommer 1932, en PAAA R79121. 
ibañistas no habían tenido tiempo para reunirse y dar un golpe decisivo. Ibáñez intentó superar esos inconvenientes, moviéndose entre las distintas unidades para recabar los apoyos necesarios. Pero no consiguió que el actual cuerpo de oficiales lo siguiera de manera cerrada. De hecho las unidades más importantes, dotadas de armamento moderno (ametralladoras pesadas y tanques), las escuelas de infantería y de aviación, permanecieron fieles a Dávila”. Además este aprovechó la poca decisión y seguridad demostrada por el ex gobernante para terminar por alejarlo de la capital y luego conseguir que dejara el país. "Sin duda su carácter irresoluto le ha hecho perder el apoyo de sus adherentes”, concluía el diplomático germano ${ }^{99}$.

De hecho a fines del mes de julio Carlos Ibáñez estaba otra vez viajando al extranjero. No participaría en los acontecimientos que terminaron con la caída del gobierno de Dávila unos meses después ${ }^{100}$.

Como bien se sabe, la elección de Arturo Alessandri como presidente de la República a fines del año 1932, pondría fin al período de creciente inestabilidad que se había vivido en Chile desde la caída de Ibáñez ${ }^{101}$. Así lo entendía también el representante del gobierno alemán, el que por fin captaba que el "León" no era precisamente un peligroso exponente de la extrema izquierda chilena, como había señalado muchas veces. "Si antes Alessandri aparecía como representante de las ideas socialistas, ahora figura como exponente de los sectores moderados del proletariado y de la democracia burguesa" ${ }^{102}$.

\section{CONCLUSIÓN}

La diplomacia alemana de los años finales de la República de Weimar mantuvo hasta el final una visión en general positiva tanto del gobierno como sobre todo de la figura y personalidad del presidente de la República de Chile y líder del movimiento militar Carlos Ibáñez del Campo. Ello explica el que se vieran absolutamente sorprendidos por la rapidez con que se desarrollaron los acontecimientos que precipitaron su caída y también con la incapacidad que mostró Ibáñez para recuperar el poder en medio de la anarquía dominante durante aquellos meses en que se constituyó la República Socialista. Pese a ello supieron prever que al general Ibáñez todavía le esperaba una larga carrera política.

${ }^{99}$ Idem.

${ }^{100}$ Telegrama de 24 de julio de 1932, en PAAA R79106 y Informe de 20 de julio de 1932, en PAAA R79105, en el que se señalaba la posibilidad de que Ibáńez y su familia viajaran a Europa, con posibilidades de visitar Alemania, se recomendaba que se lo tratara muy bien en vista de las gran admiración que siempre había mostrado por lo germano y porque "no puede excluirse que el General Ibáñez vuelva a jugar un papel importante en la vida política chilena”.

${ }^{101}$ Para el segundo gobierno de Alessandri puede consultarse FERMANDOIs, Joaquín, Abismo y cimiento: Gustavo Ross y las relaciones entre Chile y Estados Unidos 1932-1938 (Santiago, Ediciones Universidad Católica de Chile, 1997).

${ }^{102}$ Informe de 9 de noviembre de 1932, en PAAA R79069. 


\section{BiBLIOGRAFÍA}

Material de Archivo

Politischen Archiv des Auswärtigen Amts

R 79069 Politisches Beziehungen Chiles zu Deutschland 4.20 - 7.32

R 79091 Innere Politik, Parlaments-und Parteiwesen Chile 4.20 - 5.36

R 79093 Innere Politik, Parlaments-und Parteiwesen Chile 4.20 - 5.36

R 79094 Innere Politik, Parlaments-und Parteiwesen Chile 4.20 - 5.36

R 79105 Staatsoberhäupter und deren Familien, Chile 10.20 - 1.33

R 79106 Staatsmänner einschl. der Mitglieder der diplomatischen und konsularischen

Auslandvertretungen - Chile $12.20-11.35$

R 79121Sozialismus, Bolchewismus, Kommunismus usw. in Chile $4.20-2.36$

\section{Literatura}

Ahumada, Arturo, El Ejército y la revolución de 5 de septiembre de 1924 (Santiago, 1931)

Aldunate Phillips, Raúl, Ruido de sables (Santiago, Escuela Lito-tipográfica "La Gratitud Nacional”, s. d)

Arancibia Clavel, Patricia (Editora) - Balart Páez, Francisco - Brahm García, Enrique - SAN Francisco, Alejandro, El Ejército de los chilenos 1540-1920 (Santiago, Editorial Biblioteca Americana, 2007)

Barros, Mario, Historia diplomática de Chile (1511-1938) (Barcelona, Ediciones Ariel, 1970)

BennetT, Juan Pablo, La revolución de 5 de septiembre de 1924 (Santiago, Balcells y Cía. Editores, s.d.).

Bernedo, Patricio, Prosperidad económica bajo Carlos Ibáñez del Campo 1927-1929. La dimensión internacional de un programa económico de gobierno, en Historia, 24 (Santiago, 1989).

Bertolino Rendic, Mauricio, Primer gobierno del general Carlos Ibánez del Campo (1927-1931), Tesis para optar al grado de Licenciado en Derecho, Facultad de Derecho P. Universidad Católica de Chile (Santiago, s.d.) (inédita).

Blancpain, Jean Pierre, Les Allemands au Chili (1816-1945) (Köln-Wien, Böhlau, 1974).

Blancpain, Jean Pierre, Los alemanes en Chile (1816-1945) (Santiago, Hachette, 1985).

Brahm García, Enrique - Bertelsen Repetto, Raúl - Amunátegui Echeverría, Andrés, Régimen de gobierno en Chile. ¿Presidencialismo o parlamentarismo? 19251973 (Santiago, Editorial Jurídica de Chile, 2002).

Brahm García, Enrique, Carlos Ibáñez del Campo: el surgimiento de un caudillo político revolucionario, en ARANCIBIA MatTAR, Jaime - Martínez EstaY, José Ignacio (coordinadores), La primacía de la persona. Estudios en homenaje al profesor Eduardo Soto Kloss (Santiago, LegalPublishing, 2009).

Brahm García, Enrique, Hitler y la Segunda Guerra Mundial (Santiago, Editorial Universitaria, 1999).

Brahm García, Enrique, La carrera militar de Carlos Ibáñez del Campo 1909-1919, en Boletín de la Academia Chilena de la Historia, 119 (Santiago, 2010). 
Brahm García, Enrique, La elección presidencial de 1925. El candidato equivocado, en San Francisco, Alejandro - Soto, Ángel, Camino a La Moneda. Las elecciones presidenciales en la historia de Chile 1920-2000 (Santiago, Centro de Estudios Bicentenario, 2005).

Brahm García, Enrique, Manuel Montt y la colonización de Llanquihue, en Manuel Montt educador, legislador, gobernante y magistrado. Estudios en conmemoración del bicentenario de su nacimiento (1809-2009) (Santiago, Fundación Manuel Montt, 2009).

Brahm García, Enrique, Preparados para la guerra. Pensamiento militar chileno bajo influencia alemana 1885-1930 (Santiago, Ediciones Universidad Católica de Chile, 2003).

Brahm García, Enrique, Propiedad sin libertad: Chile 1925-1973. Aspectos relevantes en el avance de la legislación socializadora (Santiago, Ediciones Universidad de los Andes, 1999)

Bravo Lira, Bernardino, Historia de las instituciones políticas de Chile e Hispanoamérica (Santiago, Editorial Jurídica de Chile, 1986).

Collier, Simon - SATER, William, Historia de Chile 1804-1994 (Cambridge University Press, 1998).

Cordero Rebolledo, Raúl Andrés, Ibánez y la crisis de 1930-1931, Tesis para optar al grado de Licenciado en Historia, Instituto de Historia P. Universidad Católica de Chile (Santiago, 1994).

Correa Prieto, Luis, El presidente Ibáñez. La política y los políticos. Apuntes para la Historia (Santiago, Editorial Orbe, 1962).

Correa, Figueroa - Jocelyn-Holt - Rolle - Vicuña, Historia del siglo XX chileno (Santiago, Sudamericana, 2001).

Donoso LeTELIER, Crescente, Notas sobre el origen, acatamiento y desgaste del régimen presidencial. 1925-1973, en Historia, 13 (Santiago, 1976).

EICHENHOFER, Eberhard, Geschichte des Sozialstaats in Europa (München, C.H. Beck, 2007).

Fermandois, Joaquín, Abismo y cimiento: Gustavo Ross y las relaciones entre Chile y Estados Unidos 1932-1938 (Santiago, Ediciones Universidad Católica de Chile, 1997).

Fermandois, Joaquín, Mundo y fin de mundo. Chile en la politica mundial 1900-2004 (Santiago, Ediciones Universidad Católica de Chile, 2005).

GÓngora, Mario, Ensayo histórico sobre la noción de Estado en Chile en los siglos XIX y XX (Santiago, Ediciones La Ciudad, 1981).

Hildebrand, Klaus, Das vergangene Reich. Deutsche Aussenpolitik von Bismarck bis Hitler (Stuttgart, DVA, 1996).

Kolb, Eberhard, Die Weimarer Republik (München, Oldenbourg, 2009).

Kolb, Eberhard, Gustav Stresemann (München, Beck, 2003).

Loveman, Brian y Lira, Elisabeth, Los actos de la dictadura. Comisión investigadora, 1931 (Santiago, LOM Ediciones, 2006).

Millar Carvacho, René, Pasión de servicio. Julio Philippi Izquierdo (Santiago, Ediciones Universidad Católica de Chile, 2005).

Millar Carvacho, René, Significado y alcances del movimiento militar de 1924, en "Memoria Chilena" (www.memoriachilena.cl).

Monreal, Enrique, Historia completa y documentada del periodo revolucionario 19241925 (Santiago, Imprenta Nacional, 1929). 
NunN, Frederick M., La elección presidencial de 1927. Un final esperado y profético a la vez, en San Francisco, Alejandro - Soto, Angel, Camino a La Moneda. Las elecciones presidenciales en la historia de Chile 1920-2000 (Santiago, Centro de Estudios Bicentenario, 2005).

PYтA, Wolfram, Hindenburg: Herrschaft zwischen Hohenzollern und Hitler (München, Pantheon Verlag, 2009).

RodrígueZ Mendoza, Emilio, El golpe de Estado de 1924. Ambiente y actores (Santiago, Ercilla, 1938).

SÁEZ, Carlos, Recuerdos de un soldado. El Ejército y la política (Santiago, Biblioteca Ercilla, 1933)

Silva, Silva, Villalobos - Estellé, Historia de Chile (Santiago, Editorial Universitaria, 1976).

STraWridge, Jr., George, Militarism and Nationalism in Chile 1920-1932 (University of Pennsylvania, Ph. D., 1968) (inédita).

Valencia Avaria, Luis, Anales de la República (2a edición, Santiago, Editorial Andrés Bello, 1986).

Vial, Gonzalo, Carlos Ibánez del Campo (Santiago, Ediciones Aifos Ltda., 2007).

VIAL, Gonzalo, Historia de Chile (1891-1973), IV: La dictadura de Ibáñez (1925-1931) (Santiago, Editorial Fundación, 1996).

VIaL, Gonzalo, Historia de Chile (1891-1973), V: De la República Socialista al Frente Popular 1931-1938 (Santiago, Editorial Zig-Zag, 2001).

VIaL, Gonzalo, Historia de Chile (1891-1973), Volumen III, Arturo Alessandri y los golpes militares (1920-1925) (Santiago, Editorial Santillana del Pacífico, 1986).

VIAL, Gonzalo, Las elecciones presidenciales de 1931 y 1932. El retorno del León, en, San Francisco, Alejandro - Soto, Ángel, Camino a La Moneda. Las elecciones presidenciales en la historia de Chile 1920-2000 (Santiago, Centro de Estudios Bicentenario, 2005). 